\title{
ASSESSMENTS OF THE GRAVEL ROAD DETERIORATION HAVING LACK OF MAINTENANCE: CASE STUDY IN JIMMA ZONE
}

\author{
Eba Kitata Kenea ${ }^{1}$ and Tarekegn Reta Mesfin ${ }^{2}$ \\ ${ }^{1}$ Lecturer,Department of Civil Engineering, Assosa University,Ethiopia \\ ${ }^{2}$ Lecturer, Department of Civil Engineering, Assosa University, Ethiopia \\ Email: \{'tulugada@gmail.com, ${ }^{1}$ tare.b.ayana@gmail.com\}
}

\begin{abstract}
Gravel roads deterioration with absence of maintenance is one of the serious issue and common problem in the world. It's majorly affected by deterioration which manifests as removing from gravel road materials with the major factors such as traffic volume and environmental conditions Jimma zone might have been a standout amongst those ranges influenced toward the issue for gravel way absence of maintenances. In order to achieve the objectives of the study, the researcher was used questioner survey. To achieve this, first identified the road sections those having lack of maintenance on time existed in the study area. Then the representative road (Sarbo-Busa, Saka-Ushane and Buxure-Sanxama) and questioner surveys samples have been selected by non-probabilistic purposive and systematic sampling respectively. The questioner's survey was focused on identifying the causes of absence of maintenance and pre-conditions considered. Questioner survey was analyzed by RII. The absence of maintenance was occurred due to lack of budget fund, poor management, lack of skilled manpower, lack of good material quality, lack of regular inspections, poor working environments. The pre-conditions considered while maintaining the gravel roads are: Cost of maintenance, class as the road, maintenance schedule, skilled manpower, topography, number of road users, traffic volume, and economic standards of the society and location of the road from the center. In Jimma zone the deteriorations of gravel roads has been increasing with the absence of maintenance time.
\end{abstract}

Keyword: Gravel Road, Deterioration, Maintenance Delays, Surface Materials

\section{Introduction}

Roads are a critical asset and should be properly maintained no matter their magnificence or function to decorate their sustainability and overall performance. Globally, gravel road comprises the more proportion of the period of public roads in rural areas in developing areas Petts et al. [1]. It accounts for nearly sixty percent of the principal road network. Gravel road would vital parts furthermore incredulous of the way transportation. For huge numbers creating universal locations, additional over seventy-five percent of those way system comprises of gravel what's more world road Rajkamal et al. [2].

The total road network in the Ethiopia, gravel road shares $82 \%$ all road networks [3]. The total length of the road in Ethiopia has 56,100 kilometers of both gravel and asphalt road asset, ERA had 24,550 kilometers and the regional road authorities had 31,550 kilometers [3]. The regularly happening weathered rock inside a particular particle-size range, gravel way may be aggravator surfaced road same times alluded should similarly as unpaved road [4].

Gravel is utilized for surfacing provincial road what's more settled on from regular aggregates [5]. It became no longer best carry traffic's masses but also be proof against shear deformation and wear i.e. they have got enough class and sturdiness. The road deterioration manner begins immediately after starting to traffic. Because of the motion of site traffics and climatic adjustments over a period of time, the problems with gravel are numerous like gravel loss, safety chance, soreness and nuisance, air pollutants, and inaccessibility of roads at some point of rainy season [6].

Traffic volumes for diverse ecological part needed the elementary variables on upgrade gravel misfortune accuse.
Gravel passing rates from claiming roughly $25-30 \mathrm{~mm}$ thickness a quite a while as stated by one hundred motors steady with day will be predicted, relying on precipitation and materials properties (mainly plasticity [7]. This procedure begins off advanced exceptionally gradually in place that it has the capacity with presently not a chance to be important, and about whether it quickens at snappier costs as postpone maintenance has been proceeded. Those assessment from claiming distresses thru this approach, contending that the impacts accepted didn't outfitted with an ${ }^{1}$ exact estimation of the states of the whole way surface Rivera et al [8].

\section{Materials and Methods}

\subsection{Study area}

The study was conducted at Jimma zone, southwestern Ethiopia. Which is located $335 \mathrm{~km}$ by road southwest of Addis Ababa. Its geographical coordinates are between $7^{\circ}$ $13^{\prime}-8^{\circ} 56 \mathrm{~N}$ latitude and $35^{\circ} 49^{\prime}-38^{\circ} 38^{\prime} \mathrm{E}$ longitude. The topographic features elevations vary from $1000 \mathrm{~m}$ to 3360 above sea level. The town is found in an area of average altitude, of about $5400 \mathrm{ft}$. (1780 m) above sea level. It lies in the climatic zone locally known as woyinadega.[9]

The study was conducted on the three selected gravel roads (Sarbo-Busa, Saka-Ushane and Buxure-Sanxama) found in Jimma zone wereda. The general characteristics of those three selected road were discussed in the

\footnotetext{
${ }^{1}$ Mr. Eba Kitata, Lecturer, Department of civil engineering, College of engineering, Assosa Universitywww.asu.edu.et, Assosa, 5220, Ethiopia, Email -tulugada@gmail.com ${ }^{2} \mathrm{Mr}$. Tarekegn Reta, Lecturer, Department of civil engineering, College of engineering, Assosa University, Assosa, 18 (Postal Code-5220),Ethiopia.Email-tare.b.ayana@gmail.com *Mr. Tarekegn Reta
} 
following paragraph. The road Sarbo-Busa has found in Karsa wereda and located $42 \mathrm{~km}$ by road northeast of Jimma city. The road Saka-Ushane has found inSaka Chekorsawereda and located $34 \mathrm{~km}$ by road South West of Jimma city. The road Buxure-Sanxama has found in Mana wereda and located $22 \mathrm{~km}$ by road northeast of Jimma city.The altitude of this wereda ranges from 2250 to 3010 meters above sea level Oromia.[10].

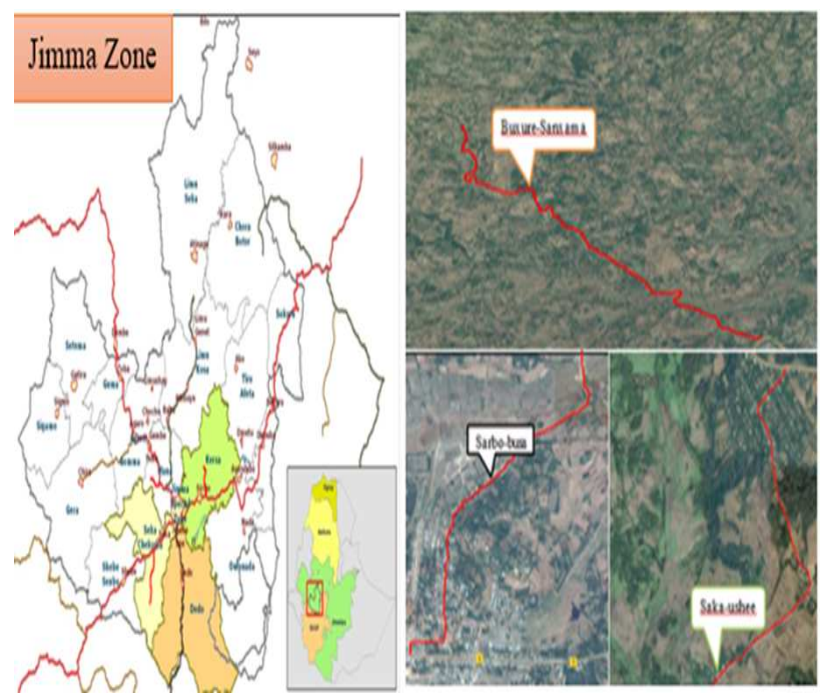

Fig 1:Map of the study area \& selected gravel road sampled. Source: Google map of the earth

\subsection{Sample size and selections}

The objective of sampling turned into to provide a practical approach of permitting the facts collection and processing components of studies to be executed whilst ensuring that the pattern affords a very good illustration of the population this is the sample turned into representative [11]. Due to the fact that whole facts approximately the populace, sampling strategies has been used for this research turned into non-probability purposive sampling \& systematic sampling. Non-probability purposive sampling has been used to select population of gravel road

\subsection{Data collections}

For this study, questioner survey was the main method of data collection. The studies questionnaire contained twenty-four questions related with the reasons and absence of maintenance had been identified thru literature review and dialogue with some events worried in Jimma zone road authority. The questionnaire turned into developed in order to compare the cause's absence of maintenance on the gravel road deteriorations

\subsubsection{Sampling Procedures and Analysis}

The researcher targeted on the road geometric standard DC2 (collectors and feeder). In Ethiopia, the majority of the road network is gravel road and in the targeted area. According to Jimma zone road authority, the majority of gravel road population was DC2. In this study, the gravel road samples were taken from the road networks of interest were identified by first gathering information's from zonal road authority and to identify best road project. The gravel road samples were taken those maintenance times already absented for one-year, two years, \& three years were selected.

\subsection{Questioner surveys procedures}

The sample required for questioner survey were fixed by using systematic sampling. The most common form of systematic sampling is an equal probability method where every Kth case in the population frame is selected for inclusion in the sample. Once the population frame is randomized, the next step is to decide on the sampling interval. The confidence level set in determining the sample size is $95 \%$ confidence level of the target population while the response is taken to be within positive or negative $5 \%$ (+ or $-5 \%$ ) of the population. The sample size for the population was calculated using the formula below [12].

$\mathrm{n}=\frac{\mathrm{z}^{2} \mathrm{pqN}}{\mathrm{e}^{2}(\mathrm{~N}-1)+\mathrm{Z}^{2} \mathrm{pq}}$

Where;

$\mathrm{N}$ - Size of the population

$\mathrm{P}$ - Sample proportion

$\mathrm{n}$ - Size of the sample

$q-1-P$

e - Accepted error ( $\mathrm{e}=0.05$, this is because estimate should be within $5 \%$ of the true value)

$\mathrm{Z}$ - The value of the standard deviation at a given confidence level.

\subsection{Questioner survey analysis.}

The questioner categorized into two main components. The first one is the questions related to the preconsiderations while maintaining the gravel roads thirteen's questions and the second one where focused on the causes of absence of maintenance contains ten questions. Totally twenty-three questions related to gravel road maintenance conditions in Jimma zone were provided for the respondents.

Not Significant (N.S.) 0\% absence contributing factors; Slightly Significant (S.S.) $<35 \%$ absence contributing factors; Moderately Significant (M.S.) 35-60\% absence contributing factors; Very Significant (V.S.) $60-75 \%$ absence contributing factors; Extremely Significant (E.S.) $>75 \%$ absence contributing factors. The collected data were analyzed through the statistical techniques and indices. Following formula is used for calculating the RII used to analyze the issue of the causes gravel road absence of maintenance in study area.

Relative Importance Index (RII)

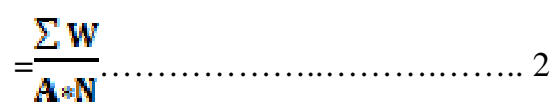

$\mathrm{W}=$ Weighting given to each cause by respondent ranges from 1 to 5 where ' 1 ' is N.S. and ' 5 ' is E.S., A = Highest weight i.e. ' 5 ' in this case, $\mathrm{N}=$ Total number of respondents identified causes are classified into five groups depending upon their RII. It is very difficult to 
suggest the possible measures to each and every absence because lies in the questionnaire, so attempts are made to suggest the possible measures to those causes, which are E.S. and pertains maximum contribution as an absence maintenance factors.

\section{Results and Discussions}

3.1 Response Rate

Table.1: Questionnaires distributed and response rate.

\begin{tabular}{|l|l|l|l|l|l|}
\hline \multirow{2}{*}{$\begin{array}{l}\text { Respond } \\
\text { ents }\end{array}$} & \multicolumn{2}{|l|}{$\begin{array}{l}\text { Questionnaires } \\
\text { Distributed }\end{array}$} & \multicolumn{2}{l|}{$\begin{array}{l}\text { Questionnaires } \\
\text { Returned }\end{array}$} & \multicolumn{2}{l}{$\begin{array}{l}\text { Respo } \\
\text { nse } \\
\text { rate in } \\
(\%)\end{array}$} \\
\cline { 2 - 5 } & Number & $\begin{array}{l}\text { Percent } \\
(\%)\end{array}$ & Number & $\begin{array}{l}\text { Percent } \\
(\%)\end{array}$ & 85.71 \\
\hline 1.Clients & 21 & 63.63 & 18 & 54.54 & 85 \\
\hline $\begin{array}{l}\text { 2.Consul } \\
\text { tants }\end{array}$ & 12 & 36.36 & 11 & 33.33 & 91.66 \\
\hline Total & 33 & 100 & 29 & 87.87 & 87.87 \\
\hline
\end{tabular}

\subsection{Pre-Conditions considerations whilst maintenances (client prospective)}

The respondent evaluations approximately the preattention for the duration of gravel avenue preservation have been explained \& mentioned based totally at the Figure 2 have been available in the following paragraphs. In line with the results obtained from evaluation based RII, $75.6 \%$ of the respondents feel that the fee of gravel road may be determine as pre-conditions concerns whilst keeping the gravel avenue.73.3\% of the respondent feel that the quantity of road users can be apprehend because the pre-conditions even as preserving. $70 \%$ of respondent feel that financial widespread of the society can be determine as pre-situations preservation. $68.9 \%$ of respondents feel that selected materials used for any gravel road can be recognize the pre-situations maintenance.

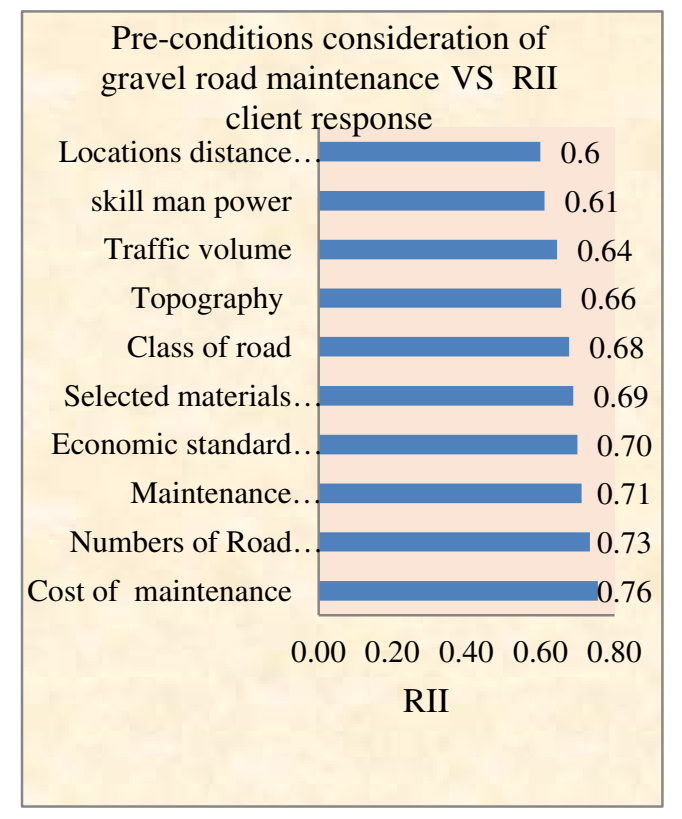

ISSN (Print): 2456-6411 | ISSN (Online): 2456-6403
Fig 2: pre-conditions considerations whilst maintenance absence client prospective.

\subsection{Causes of the gravel road deteriorations with maintenances absence client prospective.}

The effects of the respondents' evaluations based at the questioner end result of the reasons of absence of maintenances at the gravel road deteriorations have been defined \& discussed inside the Figure 3.the result suggests, $77.8 \%$ of the respondent feel that bad road maintenance control machine may be understood because the first and main causes of gravel avenue loss of maintenance's. $76.7 \%$ of respondent feels that loss of price range fund needed for gravel avenue preservation may be discerned as the second one causes of gravel avenue loss of maintenance.72.2\% respondent feel that absence of skilled/professional manpower can be understood the reasons of gravel road loss of maintenances. $57.6 \%$ respondent feels that poor regular inspection may additionally determine because the reasons of gravel road absence of maintenance. $54.4 \%$ of respondent's experience that awful climatic situations may be understood as the reasons of gravel road absence of maintenance. $53.3 \%$ respondent experience that respondent feel that poor working environment in the organizations may understand as the causes of gravel road having absence of maintenance.

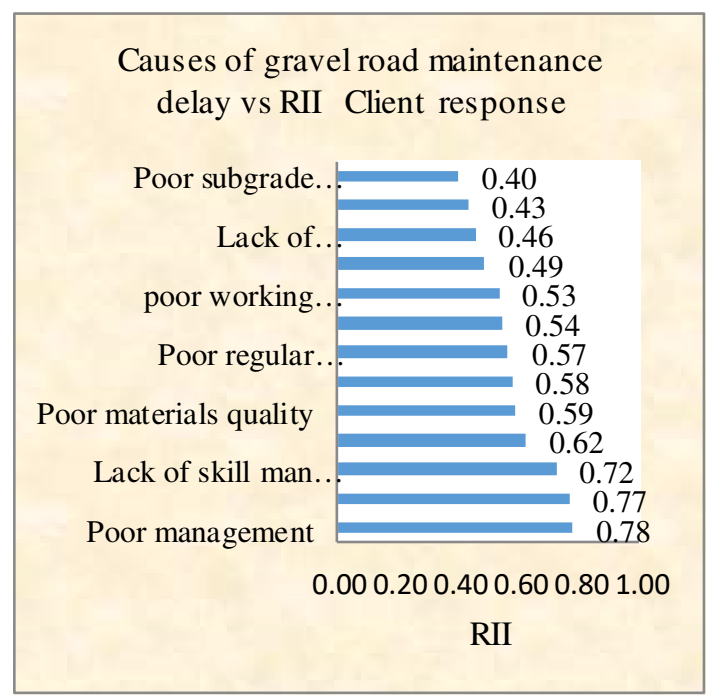

Fig 3: Causes of maintenances absence client prospective.

\subsection{Pre-condition considerations whilst maintenance (Consultant prospective)}

Respondent opinion on the pre-conditions consideration while maintaining the gravel road were explained in the following paragraph. According to that $89.1 \%$ respondent feels that class of the road may be discerned as the first pre-condition consideration during gravel road maintenance. $81.8 \%$ respondents feel that the cost of maintenances may understand as the second pre-condition consideration during gravel road maintenance. $80 \%$ respondents feel maintenance schedule may discern as the pre-condition consideration while gravel road maintenance. $74.5 \%$ respondent feel that selected materials haul distance may be understood as the pre-condition 
consideration during gravel road maintenance. $72.7 \%$ of respondents feel that absence of skilled manpowered may discern as the pre-condition consideration during gravel road maintenance

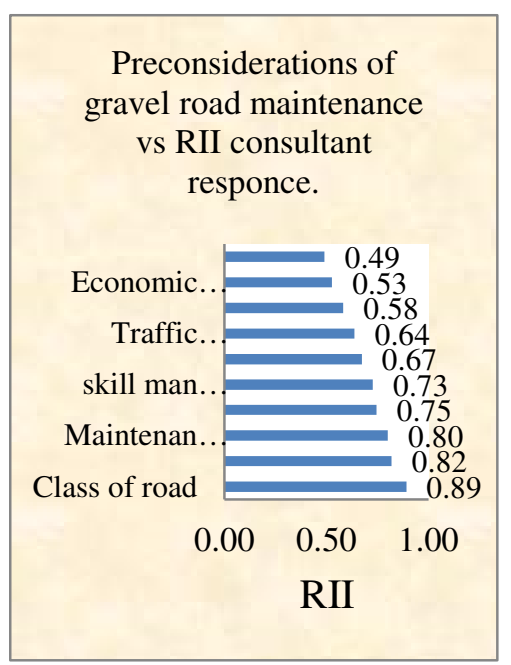

Fig 4: Shows the pre-condition consideration while maintains consultant prospective.

\subsection{Causes of absence of maintenance consultant prospective}

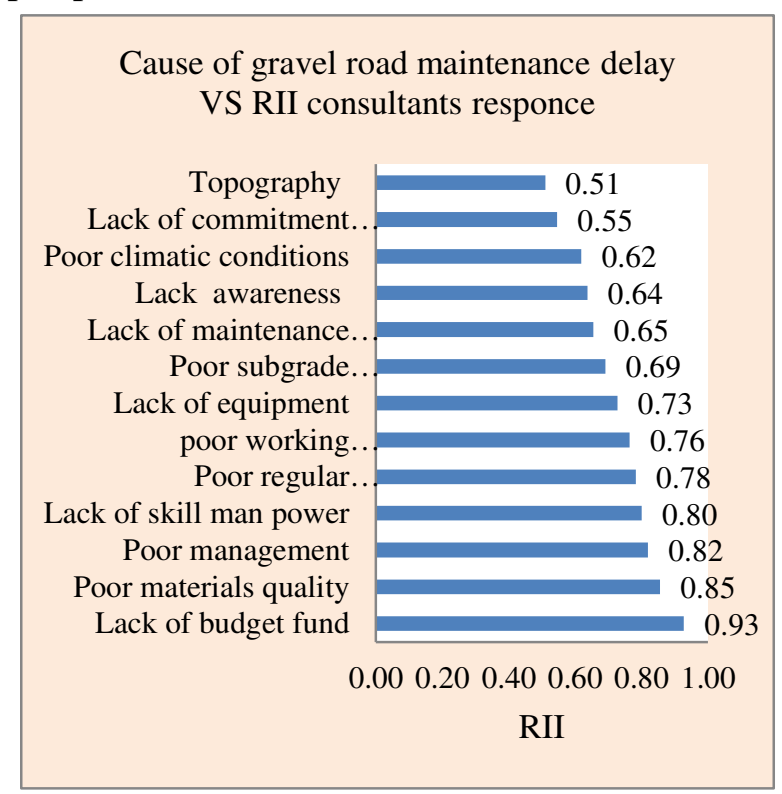

Fig 5: Shows causes of gravel road maintenances absence consultants prospective

Respondent's opinion on the causes of absence of maintenance on the gravel road deteriorations were explained in the following paragraph. According to that $92.7 \%$ of respondents feel that absence of budget fund for gravel road maintenance system may be understood as the first \& causes of gravel road absence of maintenance's.85.5\% of respondent feel poor materials quality may be discerned as the causes of gravel road absence of maintenance.81.8\% respondent feel that absence of poor management may discern as the causes of gravel road absence of maintenance. $80.0 \%$ of respondent feel that absence of skilled manpowered may understand the causes of absence of maintenance's. $78.2 \%$ of respondents feel that poor regular inspections may be understood as the causes of absence of meintenance.76.4\% respondent feel that poor working environment in the organizations administered the gravel road may discern as the causes absence of maintenance. $72.7 \%$ respondent feels that absence of equipment is also the causes of gravel road absence of maintenance. $69.1 \%$ respondents feel that poor sub-grade materials may be discerned as the causes of gravel road absence of maintenances. $65.5 \%$ respondent feel that absence of maintenance standard manuals effects the gravel road maintenance in the organizations may be discerned as the causes of gravel road absence of maintenance.

Table 2: Ranking causes of absence and gravel road maintenance pre-considerations. (Client \& consultants prospective)

\begin{tabular}{|c|c|c|c|c|c|c|c|}
\hline \multicolumn{2}{|r|}{$\begin{array}{l}\text { Pre-conditions considerations while } \\
\text { maintaining gravel road \& Causes of }\end{array}$} & \multirow{2}{*}{\begin{tabular}{|c|}
$\begin{array}{c}\text { Number of responded } \\
\text { out of } 18 \\
\text { respondents(client) RII } \\
\text { value }\end{array}$ \\
\end{tabular}} & \multirow{2}{*}{ RANK } & \multirow{2}{*}{$\begin{array}{c}\text { Number of responded out } \\
\text { of } 11 \\
\text { respondents(consultants) } \\
\text { RII value }\end{array}$} & \multirow{2}{*}{ RANK } & \multirow{2}{*}{$\begin{array}{c}\text { AVERAGE } \\
\text { RIII }\end{array}$} & \multirow{2}{*}{$\begin{array}{c}\text { RANK BASED } \\
\text { ONRII } \\
\text { AVERAGE }\end{array}$} \\
\hline № & $\begin{array}{c}\text { Pre-conditions considerations while } \\
\text { maintaining gravel road :- }\end{array}$ & & & & & & \\
\hline 1 & Costof maintenance & 0.756 & 1 & 0.818 & 2 & 0.787 & 1 \\
\hline 2 & Class of road & 0.678 & 6 & 0.891 & 1 & 0.784 & 2 \\
\hline 3 & \begin{tabular}{|l|l} 
Maintenance schedule \\
\end{tabular} & 0.711 & 3 & 0.800 & 3 & 0.756 & 3 \\
\hline 4 & Selected materialshaul distance & 0.689 & 5 & 0.745 & 4 & 0.717 & 4 \\
\hline 5 & skill man power & 0.611 & 9 & 0.727 & 5 & 0.669 & 5 \\
\hline 6 & Topography & 0.656 & 7 & 0.673 & 6 & 0.664 & 6 \\
\hline 7 & Noof road users & 0.733 & 2 & 0.582 & 8 & 0.658 & 7 \\
\hline 8 & Traffic volume & 0.644 & 8 & 0.636 & 7 & 0.640 & 8 \\
\hline 9 & Economic standard of the society & 0.700 & 4 & 0.527 & 9 & 0.614 & 9 \\
\hline \multirow[t]{2}{*}{10} & Locationsdistance consideration & 0.600 & 10 & 0.491 & 10 & 0.545 & 10 \\
\hline & Major causes of maintenance delays & & & & & & \\
\hline 1 & Lack of budget fund & 0.767 & 2 & 0.927 & 1 & 0.847 & 1 \\
\hline 2 & Poor managagment & 0.778 & 1 & 0.818 & 3 & 0.798 & 2 \\
\hline 3 & Lack of skill man power & 0.722 & 3 & 0.800 & 4 & 0.761 & 3 \\
\hline 4 & Poor materias quality & 0.589 & 5 & 0.855 & 2 & 0.722 & 4 \\
\hline 5 & Lack of equipment & 0.622 & 4 & 0.727 & 7 & 0.675 & 5 \\
\hline 6 & Poor regular inspections activity & 0.567 & 7 & 0.782 & 5 & 0.674 & 6 \\
\hline 7 & poor working environment in the organizations & 0.533 & 9 & 0.764 & 6 & 0.648 & 7 \\
\hline 8 & Poordimatic conditions & 0.544 & 8 & 0.618 & 11 & 0.581 & 8 \\
\hline 9 & Lack awareness & 0.489 & 10 & 0.636 & 10 & 0.563 & 9 \\
\hline 10 & Lack of maintenance standard manuals & 0.456 & 11 & 0.655 & 9 & 0.555 & 10 \\
\hline 11 & Poor subgrade materials conditions & 0.400 & 13 & 0.691 & 8 & 0.545 & 11 \\
\hline 12 & Topography & 0.578 & 6 & 0.509 & 13 & 0.543 & 12 \\
\hline 13 & Lack of commitment by the government & 0.433 & 12 & 0.545 & 12 & 0.489 & 13 \\
\hline
\end{tabular}

\subsection{Causes of absence of maintenance}

The following discussions are based on the results obtained from the average RII. The respondent's opinion on the causes of absence of maintenance in gravel road deteriorations was explained in the following paragraph. According to that $84.7 \%$ of respondent feel that lack of budget fund required for maintenance of gravel roads may discern as the first causes of gravel road absence of maintenance.79.8\% of respondent feel that poor management system in the organizations administered the road may discern as the second causes of gravel road absence of maintenance. $76.1 \%$ respondent feel that absence of skilled manpower the causes of gravel road maintenance.72.2\% of respondent feel that lack poor material quality may discern as the causes of gravel road

156 JREAS, Vol. 06, Issue 04, Oct 2021 
absence of maintenance. $67.5 \%$ of respondents feel that absence of material equipment (machine, survey equipment) may be understood as the causes of gravel road absence of maintenance.67.4\% respondent feel that poor regular inspections of the gravel road administered body e.g. Jimma zone and wereda road authority may discern as the causes gravel road absence of maintenance. $54.5 \%$ of respondent feels poor sub-grade materials may discern as the causes of absence. $54.3 \%$ of respondent of the respondent feel that topography of the gravel road located may discern as the causes of gravel road absence of maintenance. $48.9 \%$ feels that absence of commitment by the government to maintenance may be distinguished as the causes of absence of maintenances. Graphically both clients and consultant's perspective were shown in Figure 6.

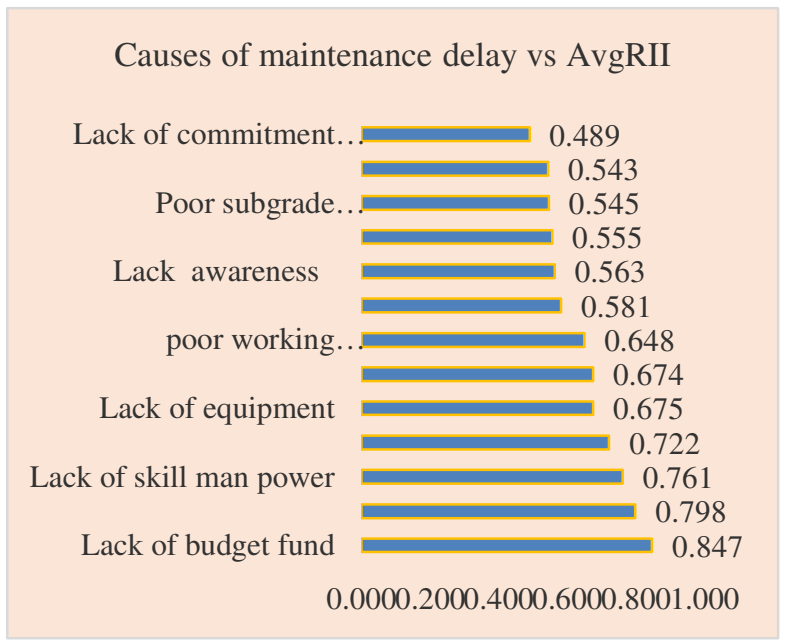

Fig 6: Causes gravel road absence of maintenance both client and consultants prospective

\subsection{Pre-conditions considerations whilst gravel road maintenance}

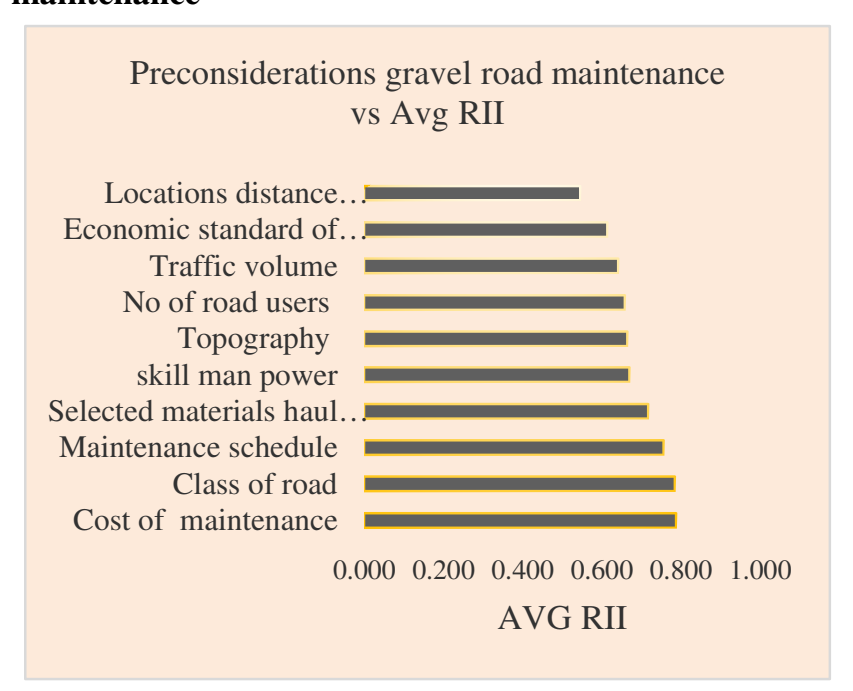

Fig 7: Graphical presentation on pre-conditions maintenance consideration

The clients and consultant opinion on the contribution towards the pre-conditions consideration while maintenances gravel based on the average RII values were detailed in the following paragraph. According to that, $78.7 \%$ of all respondents feel that cost of gravel road maintenance may discern as the first pre-conditions consideration. $78.4 \%$ of respondent feel that class of the gravel road standards may understand as the preconditions consideration. $75.6 \%$ of respondent feel that maintenance schedule may discern as the pre-conditions consideration while prioritizing gravel road maintenance $.71 .7 \%$ of the respondent feel that selected materials haul distance the gravel road needs maintenances may distinguish as the pre-conditions consideration while prioritizing gravel road maintenance. Why because most of the gravel road budget was gathered from the road users. $54.5 \%$ of the respondents feel that location of the road existed may discern as the pre-conditions consideration. Graphically both clients and consultants perspective were shown in Fig 7.

\section{Conclusions}

The major causes of gravel road with absence of maintenances has obtained from questioner responses, estimated from the average relative important index (RII) of respondents (clients and consultants) opinions, globally rural roads may make up over eighty percent of the road network length but are given lower priority in the allocation of funding because they carry much lower volumes of motorized traffic. Similarly, in this study area, eighty-four point seven percent of the respondent feel that absence of gravel road maintenance budget fund may be identified as the primary causes of the gravel road absence of maintenance's.

For most developing and emerging economies, the road maintenance challenge is dominated by the poor road maintenance management system. Similarly, in Jimma zone poor management system was the main causes of gravel road absence of maintenance. Seventy-nine point eight percent of the respondent's feel that poor management in the organizations may understand as the causes of absence of maintenance. Seventy-six pointed one percent of the respondent's may understand that absence of skilled manpower during maintenance was the causes of gravel road absence of maintenance. Fifty-eight points / pointed one percent of the total respondent's opinions may understand that poor climatic conditions (difficulty) may cause. Because as previously discussed as the majority of Jimma climatic condition was wet and difficult to maintaining gravel road regularly. Fifty-six points / pointed three percent of the respondent may understand as absence of awareness on negative impact absence of maintenance on overall effect was the cause of absence of maintenance. Fifty-five points five percent of the respondent feel that absence of gravel road maintenance standard manuals may discern as the causes of absences. Fifty-four points five percent of the respondent's opinions, poor sub-grade existed materials quality may understand the causes of gravel road maintenances absences. Fifty-four points / pointed three percent of the respondent's opinions, topographic conditions of the road required maintenances may understand as the causes of gravel road maintenances absences. The final one was forty-eight point nine percent 
of the total respondent's opinion, absence of government commitments towards gravel road maintenances may be discern as the causes of gravel road maintenances absences.

\section{Acknowledgements}

We would like to express our gratitude to Community of Jimma Zone for their constructive response to the researchers. Heartfelt gratitude is also to Assosa University.

\section{References}

[1] Petts R, Cook,J.,Dzung,B. \&Kackada,H., editor providing low cost,sustainable Access through Infrastructure Works suiTable for Small \& Medium Enterprise. Annual Conference Proceeding,Development studies Association; 2005; Vietnam: Intech-TRL.
[2] .Rajkamal K, Dinesh Reddy,T.,Rohiz,D.Venkahia.C.\& Prasad,R.K Performamce Evaluation of gravel road sections sealed with surface dressing. Transport research procedea. 2014: 81-9.

[3] ERA. Design manual of low volume road. Road meintenance booklet Part A. Addis Ababa2011.

[4] ERA. Introduction to low volume road design. Addis Ababa, Ethiophia2016.

[5] Sonjo A. Do Rural infrastructure benefits the poor? 2002.

[6] Assossiations WR. The importance of road maintenance. Paris,France: 2014.

[7] Chamoro A, Desolminihac,H.,Salgado,M.\&Barrera,E. Development and validation of methode to evaluate unpaved road condition with objectives Transport research board. 2009:3-9.

[8] Rivera F, Chamorro, A., Lucero, R., \& Aravena, C. Development of condition indicator for managing sealed rural road networks. Transport research board. 2015.

[9] .Lata D. UN-OCHA. 2009.

[10] Oromia Go. Socio-Economic profile of Jimma zone Wereda. 2006.

[11] Liu RFaA. Research Methods for construction 2007.

[12] Huntington GK, K. Gravel roads asset management. Transportation Research Circular E-C078: Roadway Preservation. 2005:214-28. 1989. 